Ege Tıp Dergisi / Ege Journal of Medicine 2018;57(1):54-56

\title{
Deforme biliyer metal stente bağlı gelişen gastrointestinal sistem kanaması
}

\section{Gastrointestinal bleeding due to deformed biliary stent}

\author{
Muhammet Yener Akpınar Fatih Saygılı Erkin Öztaş Orhan Coşkun Bülent Ödemiş \\ Türkiye Yüksek İhtisas Eğitim ve Araştırma Hastanesi, Gastroenteroloji Kliniği, Ankara, Türkiye
}

\section{Öz}

Kanama, endoskopik retrograd kolanjiyopankreatografinin (ERCP) ciddi komplikasyonlarından biri olup insidansı \%1 2 arasında değişir. Kanama sıklıkla endoskopik sfinkterotomi ile ilişkilidir, bununla beraber vaka serilerinde sfinkterotomi ilişkisiz kanamalar da bildirilmiştir. Biliyer metal stentin barsak duvarında yaptığı irritasyona bağlı oluşan kanamalar sfinkterotomi ilişkisiz kanamalara örnek gösterilebilir. Biliyer stent öyküsü olan hastaların stentin olduğu yerde ağrı ile gelmesi stentin barsak duvarına yaptığı irritasyonu akla getirir. Literatürde migre olmadan deformasyonla barsak duvarı irritasyonu yapan ve kanamaya yol açan biliyer metal stent görülmemiştir. Burada öncesinden ERCP ile biliyer metal stent konulan ve metal stentin deformasyonuna bağlı duodenumda oluşan ülserin yol açtığı kanama ile gelen hastamızı sunduk.

Anahtar Sözcükler: Endoskopik retrograd kolanjiyopankreatografi, gastrointestinal kanama.

\begin{abstract}
Hemorrhage is a severe complication of endoscopic retrograde cholangiopancreatography (ERCP) with $1-2 \%$ frequency. Hemorrhage is usually related to spinhcterotomy, however some case reports demonstrated that hemorrhagic complications are not related to sphincterotomy. Hemorrhage due to bowel wall irritation of biliary metal stent can be an example for this kind of bleedings. Pain at the site of stent must be considered for bowel wall irritation in patients with biliary stent history. In the literature hemorrhage due to bowel wall irritation associated with deformed metal stent was not reported. Here we presented our case with gastrointestinal hemorrhage due to duodenal ulcer associated with deformed biliary metal stent irritation.
\end{abstract}

Keywords: Endoscopic retrograd cholangiopancreatography, gastrointestinal hemorrhage.

\section{Giriş}

Kanama, endoskopik retrograd kolanjiyopankreatografinin (ERCP) ciddi komplikasyonlarından biri olup insidansı \%1-2 arasında değişir (1). Klinik olarak kanama ERCP esnasında akut olabileceği gibi ERCP'den günler veya haftalar sonra da ortaya çıkabilir. Kanama sıklıkla endoskopik sfinkterotomi ile ilişkilidir, bununla beraber vaka serilerinde sfinkterotomi ilişkisiz kanamalar da bildirilmiştir (2). Burada öncesinden ERCP ile biliyer metal stent konulan ve metal stentin deformasyonuna bağlı duodenumda oluşan ülserin yol açtığı kanama ile gelen hastamızı sunduk.

Yazışma Adresi: Muhammet Yener Akpınar

Türkiye Yüksek İhtisas Eğitim ve Araştırma Hastanesi,

Gastroenteroloji Kliniği, Ankara, Türkiye

Makalenin Geliş Tarihi: 30.12.2016 Kabul Tarihi: 15.02.2017

\section{Olgu Sunumu}

Yetmiş dokuz yaşında erkek hasta hastanemize kan kusma şikayetiyle başvurdu. Anamnezinde hastanın 3 ay önce lokal ileri evre pankreas kanseri tanısı aldığı ve koledoğuna $10 \times 6 \mathrm{~mm}$ boyutunda kapsız metal stent yerleştirildiği öğrenildi. Hastanın laboratuvar tahlillerinde hemoglobin: $5.8 \mathrm{gr} / \mathrm{dL}$, lökosit: $4.100 \times 10^{3} / \mathrm{uL}$, üre: 135mg/dL, kreatinin: $1.99 \mathrm{mg} / \mathrm{dL}$, INR: 0.96 olarak ölçüldü. Eritrosit transfüzyonu yapılan ve proton pompa inhibitörü infüzyonu başlanılan hastaya eş zamanlı özofagogastroduodenoskopi yapıldı. Midede hematinize kan izlendi, aspirasyon sonrası midede kanamaya yol açabilecek bir lezyon izlenmedi. Duodenum ikinci kıtada lümeni tama yakın dolduran ve metal stente yapışık olduğu görülen pıhtı izlendi. Bunun üzerine papillayı daha iyi değerlendirmek için hastaya duodenoskopi yapıldı. Stentin endoskopik olarak görünür ucundaki tellerin deforme olduğu ve lateral duvarda mukozaya gömülerek burada ülsere yol açtığı görüldü (Şekil-1a). 
Aynı zamanda papilladan sarkan metalik stentin içinde koagulum izlendi (Şekil-1b). Bu alandan sızdırır tarzda kanama mevcuttu. İlk olarak tutucu forseps ile kapsız metalik stent çıkarıldı (Şekil-1c). Stentin ülsere ettiği alanda kanamanın kendiliğinden durduğu görüldü. Daha sonra koledok selektif kanülize edildi. Kolanjiogramda intrahepatik safra yolları ve koledok proksimali belirgin genişti ve distalde darlık mevcuttu. Darlığı geçecek şekilde $10 \mathrm{~F}$ double pigtail stent yerleştirildi. İşlem sonrası kanaması olmayan hasta taburcu edildi.

Hastadan tıbbi verilerinin yayınlanabileceğine ilişkin yazılı onam belgesi alındı.

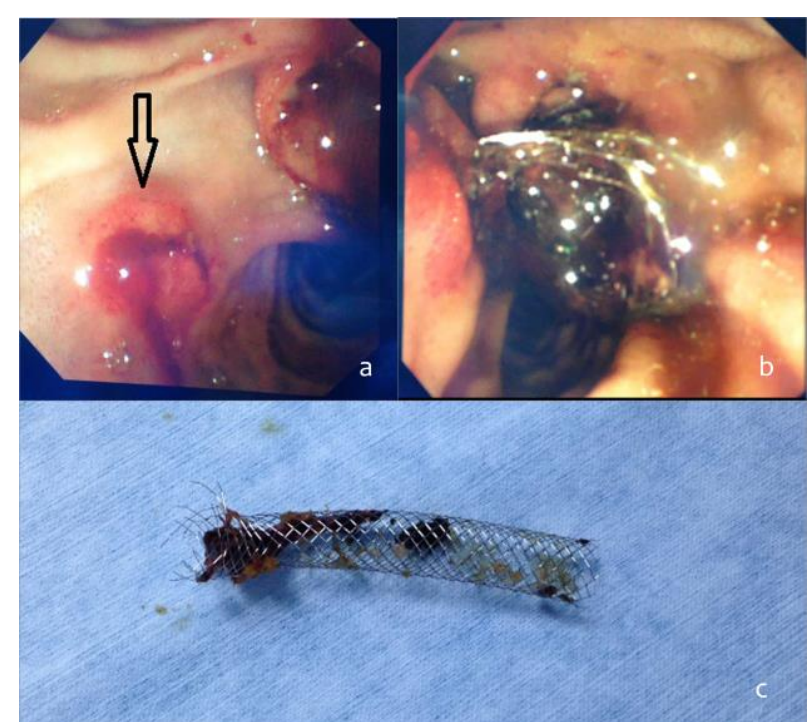

Şekil-1. a) Stentin içindeki koagulum görülüyor. b) Stentin yol açtığı kanamalı ülser (siyah ok). Ülserin üstünde papilla major görülüyor. c) Deforme olan ucu ile biliyer metalik stentin çıkarıldıktan sonraki hali görülüyor.

\section{Tartışma}

Metalik stentler günümüzde biliyer sistemin malign ve benign hastalıklarında yaygın olarak kullanılmaktadır $(3,4)$. Biliyer metalik stentler tam kaplı, parsiyel kaplı veya kapsız olabilirler. Kapsız metal stentler inoperabl malign hastalıklarda biliyer açıklığı sağlamada daha çok tercih edilirken tam kaplı metal stentler ise benign biliyer darlıklar ve sfinkterotomi ilişkili kanamalarda giderek artan sıklıkta kullanılmaktadırlar (5). Stent takılan yerde ağrı, stent migrasyonu, tümöre bağlı yada tümörle ilişkisiz stent tıkanması, stentin indüklediği ülserasyon, kanama ve perforasyon metal stentlerin iyi bilinen komplikasyonlarıdır (6-8). Merkezimizde bir yılda yaklaşık 2400 hastaya ERCP yapılmakta olup biliyer metal stentler literatürle ve kılavuzlarla uyumlu olarak biliyer sistemin malign ve benign darlıklarında, endoskopik sfinkterotomi (EST) ilişkili tip-2 perforasyonlarda ve EST sonrası kanamalarda kullanılmaktadır. Kapsız metalik stentlerde stentin tıkanması, kaplı metalik stentlerde ise stent migrasyonu literatürde bildirilen sıklıklarda izlenmektedir. Metal stent deformasyonuna bağlı kanama, merkezimizde şu ana kadar izlenmemiştir. Metal stentin deforme olması, stentin yapısındaki tellerin dışa doğru açılarak barsak duvarında ülserle beraber kanamaya yol açmasına literatürde de rastlanmamıştır.

Biliyer sisteme yerleştirilen plastik veya metal stenlerin distal migrasyonu her zaman barsak duvarı irritasyonu ve bununla ilişkili komplikasyonlar açısından risk taşır. Distal migrasyon sonrası plastik stentler sıklıkla spontan elimine olurken, metal stenlerde ise spontan eliminasyon nadirdir (9). Biliyer stent öyküsü olan hastaların stentin olduğu yerde batar tarzda ağrı ile gelmesi stentin barsak duvarına yaptığı irritasyonu akla getirir. Barsak duvarına stent irritasyonu olan bazı hastalarda ise ağrı yoktur ve stente komşu mukozada erozyon ve/veya ülserler tesadüfen endoskopide tanı alır. ERCP esnasında barsak duvarına irritasyon yapan plastik stent ya barsak duvarından serbestleştirilir ya da çıkarılı yenisiyle değiştirilir. Distale migrasyon sonucu barsak duvarını irrite eden metal stentlerin çıkarılması ise teknik olarak daha zor olup, literatürde bu vakalar için argon plazma başarılı bir şekilde kullanılmıştır (10).

Sonuç olarak ERCP sonrası gastrointestinal sistem kanaması ile başvuran hastalarda stenlerin barsak duvarında yol açabileceği erozyon ve ülserler de ön tanıda akılda tutulmalıdır. Stentin kanamalı alandan uzaklaştırılması ve takibinde barsak duvarındaki lezyona yönelik endoskopik tedavi kanamayı etkili bir şekilde kontrol edebilir.

\section{Kaynaklar}

1. Talukdar R. Complications of ERCP. Best Pract Res Clin Gastroenterol 2016;30(5):793-805.

2. Lee $\mathrm{MH}$, Tsou YK, Lin $\mathrm{CH}$, et al. Predictors of re-bleeding after endoscopic hemostasis for delayed post-endoscopic sphincterotomy bleeding. World J Gastroenterol 2016;22(11):3196-201.

3. Jiménez-Pérez M, Melgar Simón JM, Durán Campos A, González Grande R, Rodrigo López JM, Manteca González R. Endoscopic management of post-liver transplantation biliary strictures with the use of fully covered metallic stents. Transplant Proc 2016;48(7):2510-4.

4. Menon S. Hilar stenting for malignant biliary obstruction. Gastrointest Endosc 2016;83(2):478-9.

5. Pfau PR, Pleskow DK, Banerjee S, et al. Pancreatic and biliary stents. ASGE Technology Assessment Committee. Gastrointest Endosc 2013;77(3):319-27. 
6. Yu DW, Hong MY, Hong SG. Endoscopic treatment of duodenal fistula after incomplete closure of ERCP-related duodenal perforation. World J Gastrointest Endosc 2014 16;6(6):260-5.

7. Inoue T, Naitoh I, Okumura F, et al. Reintervention for stent occlusion after bilateral self-expandable metallic stent placement for malignant hilar biliary obstruction. Dig Endosc $2016 ; 28(7): 731-7$.

8. Togawa $\mathrm{O}$, Kawabe $\mathrm{T}$, Isayama $\mathrm{H}$, et al. Management of occluded uncovered metallic stents in patients with malignant distal biliary obstructions using covered metallic stents. J Clin Gastroenterol 2008;42(5):546-9.

9. $\mathrm{Ho} \mathrm{H}$, Mahajan A, Gosain S, et al. Management of complications associated with partially covered biliary metal stents. Dig Dis Sci 2010;55(2):516-22.

10. Christiaens $\mathrm{P}$, Decock S, Buchel O, et al. Endoscopic trimming of metallic stents with the use of argon plasma. Gastrointest Endosc 2008;67(2):369-71. 